\title{
A inserção da história e cultura afro-brasileiras no cotidiano escolar: um estudo de caso ${ }^{1}$
}

\author{
Davi Silvestre Fernandes Martins \\ Universidade Estadual Paulista, São Paulo -Brasil. \\ davisilvestre@gmail.com \\ Leila Maria Ferreira Salles \\ Universidade Estadual Paulista, São Paulo-Brasil. \\ leila@rc.unesp.br
}

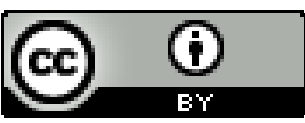

Educação: teoria e prática, Rio Claro, SP, Brasil - elSSN: 1981-8106

Está licenciada sob Licença Creative Common

\begin{abstract}
Resumo
A presente pesquisa investiga as implicações da obrigatoriedade do estudo da temática História e Cultura Afro-Brasileiras no cotidiano escolar. Procura-se analisar em que medida a promulgação de uma legislação específica pode modificar relações estabelecidas na escola. Os dados desta pesquisa, delineada como um estudo de caso, foram coletados através de questionários, entrevistas, observação, análise de documentos e grupos focais. A análise indicou que os preconceitos e relações preconceituosas existem e determinam relações conflituosas frente às quais, em geral, os educadores tendem a se omitir. A análise revelou, ainda, que o cotidiano escolar é permeado por relações de conflito etnicorraciais que adentram o espaço escolar, evidenciando que relações de poder que se manifestam por meio de preconceitos e discriminações etnicorraciais estão presentes no cotidiano das escolas. O estudo, entretanto, apontou que a atuação da escola pode contribuir para mudar a forma de pensar e de agir dos alunos, colaborando, assim, para a mudança da realidade social e das relações estabelecidas no cotidiano escolar.

Palavras-chave: Escola. Relações etnicorraciais. Cotidiano escolar. Lei 10.639.

\section{The insertion of afro-brazilian history and culture in everyday school life: a case study}

\footnotetext{
Abstract

${ }^{1}$ As análises compiladas neste texto são parte da Dissertação de Mestrado apresentada ao Programa de Pós-graduação em Educação UNESP/RC por Davi Silvestre Fernandes Martins em 2010. O texto consiste em uma revisão do trabalho apresentado no 10 Encontro de Pesquisa em Educação da Região Sudeste
} 
This research investigates the implications of mandatory of thematic study of AfroBrazilian history and culture in school daily life. It aims to analyze to what extent the promulgation of a specific law can modify relations established at school. The data from this case study were collected through questionnaires, interviews, observation, document analysis and focus groups. The analysis indicates that prejudices and biased relations still exist and determine conflicting relations on which educators generally tend to omit themselves. However, the review also indicated that the performance of the school can contribute to change the students' way of thinking and acting, thus collaborating for changing the social reality and the relations established in school daily life.

Keywords: School. Racial and ethnical relations. School daily. Law 10.639.

\section{La inserción de la historia y cultura afrobrasileñas en el cotidiano escolar: un estudio de caso}

\section{Resumen}

La presente investigación analiza las implicaciones de la obligatoriedad del estudio de la temática Historia y Cultura Afro-Brasileñas en el cotidiano escolar. Se procura analizar en qué medida la promulgación de una legislación específica puede modificar relaciones establecidas en la escuela. Los datos de esta investigación, delineada como un estudio de caso, se recolectaron a través de cuestionarios, entrevistas, observaciones, análisis de documentos y grupos focales. El análisis indicó que los prejuicios y relaciones prejuiciosas existen y determinan relaciones conflictivas frente a las que, en general, los educadores tienden a omitirse. El análisis reveló, incluso, que el cotidiano escolar es permeado por relaciones de conflicto etnorraciales que hay en el espacio escolar, evidenciando qué relaciones de poder que se manifiestan por medio de prejuicios y discriminaciones etnorraciales están presentes en el cotidiano de las escuelas. Mientras tanto, el estudio apuntó que la actuación de la escuela puede contribuir para cambiar la forma de pensar y de actuar de los alumnos, colaborando, así, para el cambio de realidad social y de las relaciones establecidas en el cotidiano escolar.

Palabras clave: Escuela. Relaciones etnorraciales. Cotidiano escolar. Ley 10.639.

\section{Introdução}

O Brasil viveu, por muitos anos, uma realidade na qual as relações etnicorraciais, a cultura e história afro-brasileiras se constituíam em uma discussão exclusivamente de negros, embora essa questão faça parte do cotidiano de todos os brasileiros. Em geral, havia uma tendência a minimizar essa questão, afirmando que os preconceitos contra os negros não eram reais, mas algo imaginado. 
O impacto das questões etnicorraciais na população brasileira pode, entretanto, ser constatado a partir de indicadores sociais, como o Índice de Desenvolvimento Humano (IDH) elaborado pela UNESCO com a finalidade de avaliar, em todos os países, o acesso à educação, saúde e renda da população. O Brasil ocupa a 75a colocação mundial no IDH, mas se considerarmos somente a população afrobrasileira, o Brasil passa a ocupar a 105a posição e, se for considerada apenas a população branca, a 44ạ colocação mundial (VICENTE, 2007).

De modo geral, a escola também silenciou por um longo tempo sobre as questões étnicas fato que contribuiu para a marginalização de toda uma população pela cor da pele e descendência afro-brasileira. Ao silenciar, ao não discutir a questão, ao mascarar práticas que resvalam em atitudes preconceituosas a escola, embora nem sempre de forma explícita, reproduz preconceitos e práticas racistas. Até mesmo os livros didáticos, como indica Oliveira (2005), tendem ao silenciamento no que diz respeito às questões etnicoculturais.

Entretanto, por força dos movimentos sociais, o quadro apontado acima tende a ser revisto e o Estado é impelido a reconhecer a existência da problemática etnicorracial na sociedade brasileira. Em 9 de janeiro de 2003 foi promulgada a Lei № 10.639, que incluiu na Lei de Diretrizes e Bases da Educação Nacional (LDB - Lei № 9.394, de 20 de dezembro de 1996) a obrigatoriedade do ensino da temática História e Cultura Afro-Brasileira (BRASIL, 1996, 2003).

Em 10 de março de 2004, complementando o disposto na lei, o Conselho Nacional de Educação (CNE) instituiu, por meio do Parecer n.ㅇ 3, as Diretrizes Curriculares Nacionais para a Educação das Relações Etnicorraciais e para o Ensino de História e Cultura Afro-Brasileira e Africana. Em 10 de março de 2008, a Lei № 11.645 alterou a LDB e a Lei № 10.639, incluindo a obrigatoriedade do estudo de História e Cultura Indígena (BRASIL, 2004, 2008).

A Lei № 10.639 propõe mudanças curriculares e institucionais na escola, que vão muito além da pura e simples inserção de um conteúdo no currículo ao ter como objetivo que os educandos questionem a concepção que apregoa a superioridade branca, e os mitos a ela correlatos, e a inferioridade negra e indígena, neles introjetados pela cultura racista na qual foram socializados. O Parecer CNE/CP 3 (BRASIL, 2004) propõem que o currículo escolar considere, reconheça e valorize a 
história, a cultura e a identidade afrodescendente com o objetivo de combater o racismo e as discriminações que atingem os afro-brasileiros:

Aos estabelecimentos de ensino está sendo atribuída responsabilidade de
acabar com o modo falso e reduzido de tratar a contribuição dos africanos
escravizados e de seus descendentes para a construção da nação brasileira;
de fiscalizar para que, no seu interior, os alunos negros deixem de sofrer os
primeiros e continuados atos de racismo de que são vítimas (BRASIL, 2004,
p.18).

O ambiente educacional deve permitir a formação de cidadãos orgulhosos de seu pertencimento etnicorracial, quer sejam descendentes de africanos, povos indígenas, europeus ou asiáticos, para interagirem na construção de uma nação democrática, na qual todos tenham seus direitos garantidos e sua identidade valorizada (BRASIL, 2004).

Há, assim, um pressuposto presente na legislação de que a inserção no currículo escolar da temática História e Cultura Afro-Brasileira e Indígena permite aos educandos o questionamento dos mitos e um posicionamento crítico sobre a cultura racista na qual foram socializados. Mas, será que isso acontece? Ou seja, qual o significado que teve para educadores e educandos a introdução do estudo sobre a temática história e cultura afro-brasileiras no cotidiano escolar?

Os objetivos da presente pesquisa estão, então, centrados na investigação das implicações da obrigatoriedade do estudo da temática História e Cultura AfroBrasileiras no cotidiano escolar. Procura-se analisar a possibilidade de que relações estabelecidas na escola possam ser modificadas pela promulgação de uma legislação.

Neste trabalho, os dados foram coletados através de questionários, entrevistas, observação direta, análise de documentos e grupos focais, o que vem a caracterizar o estudo como de natureza qualitativa. A pesquisa qualitativa abarca a dimensão social da pesquisa e do pesquisador e tem como premissa básica saber quem fala, de onde fala e por que fala. Trata-se de uma metodologia de investigação que enfatiza a descrição, a indução, a teoria fundamentada e os estudos das percepções pessoais (TRIVIÑOS, 1987). O estudo de caso se apresenta adequado ao escopo proposto neste estudo, porque permite o amplo e detalhado conhecimento do objeto de estudo (GIL, 1991).

Os depoimentos foram tomados de alunos e professores do último ano do fundamental, o nono ano. Com os alunos foram realizados grupos focais, técnica 
definida como a reunião propositada de pessoas selecionadas segundo critérios da pesquisa para debater a respeito do tema investigado (GATTI, 2005). Os grupos foram formados por alunos que se voluntariaram a participar da pesquisa. No total 15 alunos participaram dos grupos: 7 meninas e 8 meninos. Foram feitos 3 encontros com o grupo. Os encontros tiveram como tema gerador o estudo da cultura e da história afrobrasileira e africana na escola, as práticas, preconceitos e discriminações no cotidiano escolar.

Para assegurar que nos grupos focais todas as etnias estivessem representadas proporcionalmente, os alunos foram convidados para participar das entrevistas considerando-se os seus traços fenotípicos: negros, pardos e brancos. Entretanto, as autodeclarações dos alunos sobre sua etnia não coincidiu com os traços fenotípicos, de tal modo que, de acordo com as autodeclarações, o grupo ficou assim constituído: pardos (28,1\%); brancos (21,5\%); morenos (14,4\%); negros (07,2\%); mulatos $(07,2 \%)$; não declarados $(21,5 \%)$. Como se vê, o fenótipo percebido nem sempre se iguala à autodeclaração de etnia.

Com os docentes foram realizadas 6 entrevistas semiestruturadas: 5 professores que lecionavam para o 8 o ano e uma com o professor-coordenador. Os professores se autodeclararam brancos (33,3\%); pardos (16,7\%); afro-brasileiros (16,7\%); luso-brasileiros (16,7\%.) e multiétnicos $(16,7 \%)$.

Os dados coletados foram analisados através do método de análise de conteúdo (BARDIN, 1977). De acordo com essa autora, a análise de conteúdo consiste em um instrumental metodológico por meio do qual se busca entender o sentido de uma comunicação. A unidade de análise é o texto, compreendido nesse caso como produto das entrevistas e dos grupos focais. Os depoimentos foram analisados a partir das dimensões: os preconceitos na escola; a Lei 10.639 e as relações etnicorraciais e o cotidiano escolar.

O estudo foi realizado em uma escola estadual, situada na cidade de São Paulo, região da Vila Mariana, a poucos metros da estação de metrô Santa Cruz. Essa escola é, na medida do que sabemos, uma escola que não se destaca das demais: não é conhecida pela excelência ou pela má qualidade de seu ensino, nem por apresentar grandes incidentes envolvendo alunos e/ou educadores. É uma escola na qual o 
cotidiano escolar, vivido pelo menos aparentemente, pode ser considerado semelhante ao da maioria das escolas da região metropolitana de São Paulo.

\section{O afro-brasileiro, as relações etnicorraciais e a escola}

Toda a discussão sobre ser negro no Brasil não se restringe apenas às características físicas, mas tem implicações políticas. No parecer sobre as Diretrizes Curriculares Nacionais para a Educação das Relações Etnicorraciais e para o Ensino de História e Cultura Afro-Brasileiras e Africanas, é apontado que negro é quem assim se define (BRASIL, 2004). O termo preto é um dos quesitos utilizados pelo IBGE para classificar a cor da população brasileira, que pode se autodeclarar preta, branca, parda, indígena e/ou amarela. Entretanto, e conforme proposto pelo Movimento Negro, entende-se neste trabalho que na categoria negro estão reunidos, sem diferenciação, as pessoas que se autodeclaram pretos e pardos, dado a sua ascendência africana.

A opção por se utilizar neste texto o termo afro-brasileiro não é neutra, pois denota um posicionamento frente à questão etnicorracial. Entende-se, neste estudo, 0 conceito afro-brasileiro de acordo com a definição dada por Lopes (2006), significando um qualitativo do indivíduo brasileiro de origem africana e de tudo que the diz respeito. É relativo, ao mesmo tempo, à África e ao Brasil, indicando o brasileiro de descendência africana. O conceito afro-brasileiro é compreendido como construções ideológicas e discursivas elaboradas a partir das histórias de vida, das histórias culturais, do significado de ancestralidade e de outras influências que foram determinantes na construção da identidade negra. Assim, é possível que indivíduos fenotipicamente brancos se identifiquem em grande medida com a negritude (ASSIS; CANEN, 2004) como ocorreu nas autodeclarações dos entrevistados.

Quanto ao termo raça, entende-se que designa a construção social tramada nas tensas relações entre brancos e negros. De forma que o conceito, como é empregado neste texto, não tem relação com o conceito biológico de raça difundido no século XVIII e, hoje, totalmente obsoleto. Entretanto, o termo raça é utilizado com frequência nas relações sociais brasileiras, para informar como determinadas características físicas, como cor de pele, tipo de cabelo, entre outras, influenciam, interferem e até 
mesmo determinam o destino e o lugar social dos sujeitos no interior da sociedade brasileira (BRASIL, 2004). O emprego do termo étnico, na expressão etnicorracial, tem a finalidade de situar que essas relações tensas devidas às diferenças na cor da pele e traços fisionômicos o são também devido à raiz cultural plantada na ancestralidade africana.

As culturas afro-brasileiras têm vivenciado situações que vão de convívio pacífico com as diferentes culturas presentes na sociedade brasileira a relações marcadas por preconceitos e discriminações, tolerância, tentativas e propostas de embraquecimento da raça brasileira, o que indica a existência de uma ambivalência da sociedade frente às culturas de origem africana. Se ora parece estar presente uma relação que indica um convívio pacífico, ora parece predominar uma relação pautada em estereótipos.

Atributo, estereótipo e estigma são conceitos diretamente relacionados e implicados um no outro. Nesse sentido, o Ministério do Trabalho possui um glossário empregado nas causas judiciais, no qual define preconceito como uma indisposição, um julgamento prévio negativo que se faz de pessoas estigmatizadas por estereótipos, enquanto que discriminação é determinada como o nome que se dá para a conduta (ação ou omissão) que viola direitos das pessoas com base em critérios injustificados e injustos, tais como: a raça, o sexo, a idade e a opção religiosa, entre outros (BECCARI, 2005).

Atributo e estereótipo estão diretamente associados à noção de estigma, que podem ser subdivididos em três tipos segundo sua natureza: os de deformidades físicas, os de caráter individual e os estigmas tribais, de raça, nação e religião (GOFFMAN, 1963). Os estereótipos e discriminações servem para indicar e separar as pessoas que são consideradas normais - os sem deformidade física, sem distúrbios de personalidade, brancos etc. - dos demais que são, então, percebidos como diferentes e passíveis de sofrer discriminações. Para tanto, a sociedade estabelece normas e as pessoas são julgadas frente a essas normas de tal modo que, nós e os que não se afastam negativamente das expectativas particulares em questão, são considerados normais, enquanto os outros podem ser vistos como anormais e sujeitos a discriminações (GOFFMAN, 1963). 
Assim, no processo de construção de estereótipos, as diferenças, entre os indivíduos vão sendo demarcadas. Na demarcação das diferenças, nega-se que possa haver similaridades entre indivíduos e grupos diferentes. A diferença permite imputar ao outro um atributo que o desfavoreça e, assim, relaciona-se ao poder de incluir/excluir, de pertencer/não pertencer, de demarcar fronteiras - nós/eles - de classificar em bons/maus, racionais/irracionais, de normalizar - normais/anormais. Os indivíduos são medidos, comparados, relacionados e classificados. E, ao se hierarquizar as diferenças, as relações de poder entre os indivíduos vão sendo estabelecidas. A diferença é o modo como, por comparação, se explicita uma não igualdade, enquanto o preconceito é o resultado de um juízo ou de uma concepção não problematizada, quando o diferente é transformado no desigual e no inferior. Entretanto, lembramos aqui: a diferença não é, em si, um problema. No processo de construção das identidades sempre há referência a um outro. O problema é a discriminação e a essencialização do outro, fundamentadas nas diferenças (SALLES, 2009).

Em uma primeira aproximação com a ideia de identidade negra, percebe-se que há uma afirmação pautada em termos de cor, raça ou etnia. Mas, uma tensão permeia a discussão desses termos porque comporta contradições e hibridizações que desafiam qualquer ideia de essencialização biológica, o que conduz para o caráter de construção discursiva dessa identidade (ASSIS; CANEN, 2004).

A perspectiva do multiculturalismo alerta para a necessidade de não se congelar identidades em torno de marcadores únicos, sob pena de homogeneização dessas identidades e da perpetuação de preconceitos. Nesse sentido, o conceito de hibridização confere uma relativização à construção identitária fundada em marcadores únicos, ao apontar e assinalar as múltiplas camadas que a produzem. De outro lado, porém, a construção de identidades fundadas em marcadores únicos e em espaços específicos contribui para que os sujeitos se reconheçam em identidades coletivas, demarcando espaços de pertencimento e contribuindo para que se unam para requisitar direito à voz e superar discriminações (ASSIS; CANEN, 2004). Nesse sentido, é que no Movimento Negro está presente uma afirmação de identidade fundada na singularidade dos marcadores, visando à conquista de direitos.

Essa discussão está presente nos diferentes espaços sociais e,
consequentemente, na escola, onde, muitas vezes, a ênfase está colocada na 
afirmação dos marcadores singulares, como pode ser visto na reivindicação de políticas que buscam promover uma discriminação positiva dos afro-brasileiros como a política de cotas. Isto evidencia, como apontam Assis e Canen (2004) para a necessidade de se articularem às considerações multiculturais a hibridização e a importância dos marcadores singulares.

Um resultado disso é a promulgação da Lei 10.639, em 2003, que tornou obrigatório o ensino de História e Cultura afro-brasileiras nas escolas brasileiras e que se constitui em objeto deste estudo.

$\mathrm{Na}$ escola, mitos e estereótipos sobre o negro foram e ainda são disseminados. Há um vocabulário que, embora varie de escola para escola, pode ser, de modo geral, encontrado em todas elas e que é empregado para explicitar a separação entre os educandos estigmatizados segundo a cor da pele e os outros. Expressões como: cabelo ruim, café com leite (quando uma criança branca brinca com uma criança negra), negrice (como sinônimo de burrice), pé na cozinha, entre outras, são, ainda hoje, utilizadas conforme indicam os relatos de um grande número de estudantes.

Os livros didáticos, tal como evidenciam pesquisas de Watthier (2008), Oliveira (2005), Munanga (2000, 2005), Lima (2005) e Silva (2005), abordam poucas vezes os afrodescendentes. Há quase uma exclusão do afro-brasileiro do material didático e, quando o fazem, suas diferentes origens tendem a ser desconsideradas. O tratamento da história das civilizações negras africanas e afro-brasileiras é, em geral, superficial. As representações que predominam nos livros usados pela escola são as do negro escravo, que executa trabalho braçal e é inferiorizado intelectualmente.

Em uma pesquisa realizada sobre o afro-brasileiro nos livros didáticos de Língua Portuguesa e Literatura do Ensino Médio, adotados pela Secretaria da Educação do Estado do Paraná, no ano de 2006, e consequentemente distribuído gratuitamente na rede pública de ensino desse Estado, há um

[...] maior enfoque sobre o tempo da escravidão, e pouco se menciona sobre a ocorrência do racismo atualmente, e sobre a importância da diversidade etnicorracial na história da sociedade brasileira, não esclarecendo aos alunos o que vem a ser, realmente, o racismo e como ele é manifestado em nosso meio social (WATTHIER, 2008, p. 51).

Assim, é necessário, de acordo com a autora, um bom preparo do professor para a condução das suas aulas de maneira a realizar um trabalho que possa 
desconstruir estereótipos veiculados. No Ensino Fundamental, situações como essa também ocorrem. A pesquisa sobre os livros da coleção ALP - Análise, Linguagem $e$ Pensamento: um trabalho de linguagem numa proposta socioconstrutivista, de Língua Portuguesa e Literatura do 1 으 a 5 을 ano, apontou:

\begin{abstract}
O primeiro caso claro de discriminação ao negro detectado aparece no texto 14 do primeiro volume (pág. 80), extraído da obra Reinações de Narizinho, de Monteiro Lobato, onde se lê: "Na casa ainda existem duas pessoas - tia Nastácia, negra de estimação que carregou Lúcia em pequena..." O termo de estimação empregado pelo autor reflete uma conotação negativa, ou seja, a de comparar a negra como um animal ou coisa a que se volta especial predileção (OLIVEIRA, 2005, p. 6, grifo do autor).
\end{abstract}

Ressalta-se, aqui, que livros didáticos ou de literatura infantil como esse têm como público-alvo crianças de tenra idade. Conforme Munanga (2005) o livro didático tem um poder degenerador na constituição da autoestima e da identidade da criança negra, contribuindo para construir e reforçar sentimentos de inferioridade. Cabe lembrar que é pelo processo de socialização que ocorre a interiorização da sociedade pelo indivíduo, sendo a escola uma das instâncias que contribui para esse processo (BERGER; LUCKMANN, 2002). Isto denota a importância da correção no material didático, de tal forma que não resvale para situações preconceituosas. Para reverter esse quadro é preciso desconstruir as representações negativas do afro-brasileiro e os equívocos históricos formados no processo didático.

Estereótipos, preconceitos e discriminações permeiam as redes de subjetividade cotidianas, seja em âmbito geral seja quando a referência é a cultura negra. Desse modo, a contribuição que o ensino de História pode ter na questão do afro-brasileiro é a de permitir o entendimento da complexidade social ao problematizar os conflitos entre brancos e negros. Como disciplina escolar, a História elabora discursos sobre a realidade que podem vir a se tornar senso comum no interior de uma sociedade ou mesmo na comunidade escolar. É na busca de compreender a influência que o ensino desse conteúdo tem no cotidiano escolar que este estudo foi realizado.

\title{
3 A lei 10.639 no cotidiano escolar no depoimento dos entrevistados
}


A fala dos docentes revela que os alunos se tratam utilizando termos pejorativos, em especial, nas relações com os alunos de estereótipos diferentes como os afrodescendentes, os homossexuais e os migrantes de regiões brasileiras: "É preconceito com afrodescendente, com gay, com emo, com lésbica, com rico, com pobre, com aluna grávida, com aluna que sai com muitos garotos (docente)".

Os professores, segundo eles próprios, são os profissionais mais atuantes na escola para coibir à discriminação etnicorracial, o que se dá principalmente por meio de advertências verbais. Na maioria das vezes, o professor orienta como acha certo. Isto indica que o combate à discriminação carece de uma orientação clara, teórica e procedimental, que paute as ações e que deveria ser estabelecida no âmbito escolar ou na rede estadual de educação. Em geral, os docentes relatam que frente a situações de preconceitos e discriminação na escola procuram agir como pensam ser o mais adequado e denunciam a falta de uma política coletiva da equipe escolar para atuar em situações desse tipo. Nesse contexto eles parecem entender que leis que determinam o estudo de outras culturas, como a proposta pela Lei 10.639 , são importantes: "Eu sou negra, acho vital que meus alunos saibam a sua verdadeira história, respeite sua cor e seu cabelo, que tenha orgulho de ser como é" (docente).

Essa professora conta que, mesmo antes da promulgação da lei já procurava atuar nesse sentido, e relatou ter vivido situações de preconceito etnicorracial na sua vida pessoal e na escola.

A Lei 10.639 instituiu o ensino de História e Cultura Afro-Brasileiras como um conjunto de medidas a serem desenvolvidas ao longo do ano, por todas as esferas da educação escolar e de maneira transversal em todo o currículo. Apesar disso, a ação prática está, conforme os depoimentos, restrita à atuação de cada professor. Essa percepção se reforça quando observamos que, em nível institucional, não existem registros sobre esse tipo de ocorrências na escola.

Mesmo assim, para os docentes, o estudo da temática Cultura e História AfroBrasileiras contribui para uma diminuição de conflitos nas relações etnicorraciais. Para eles, o estudo a esse respeito somado a uma postura educativa de promoção da igualdade etnicorracial na escola possibilita que os alunos reflitam sobre essas situações e mudem seus comportamentos: 
Quando é bem estudado, muda sim. Nos atendimentos aos alunos que brigam, discutem ou são colocados para fora sala de aula, eles citam muito as coisas que a professora de história fala com eles e também da capoeira em educação física. É um início de uma mudança (docente).

As minhas aulas são um exemplo de situação que muda o comportamento deles, no início riem das músicas, depois eles pedem mais. O trato entre eles e as brincadeiras de mau gosto, mudam de sentido, passa a ser legal ser afro, saber tocar Olodum, ser bom na capoeira e aqueles que não gostam da atividade passam a entender mais e respeitam mais (docente).

A importância da Lei para alterar as relações cotidianas na escola é constantemente afirmada: "É fundamental conhecermos a nossa história de brasileiro, e é isso que o ensino de cultura e história afro-brasileira está trazendo, os elementos que faltavam pra entendermos de forma justa quem somos" (docente).

Entretanto, essas afirmações devem ser relativizadas, afinal, há uma afirmação genérica da importância do estudo que nem sempre se concretiza em ações práticas na sala de aula e na escola. Assim, três professores, apesar de afirmarem a importância do estudo dessa temática, dizem não realizar atividades com seus alunos sobre essa questão. Outras vezes, mesmo entre os docentes que abordam essa temática em suas aulas, isso é feito de forma esporádica. Assim sendo, como pode ser possível postular a mudança de comportamento pelo estudo de uma temática se o tema é escassamente estudado?

Buscando o posicionamento dos docentes frente a uma política especifica, foi perguntado a eles sobre a política social de cotas para afrodescendentes em concursos públicos. Verificou-se, então, que as posições sobre os professores a respeito das cotas são ambíguas: ora são defendidas de modo genérico ora são questionadas, pois o peso deveria ser dado ao mérito. Desse modo, acreditamos que se faz necessário colocar esse tema na pauta das discussões dos docentes e das políticas das redes públicas de educação. Afinal, como indica o Parecer da CNE (BRASIL, 2004, inserir p. 11):

\footnotetext{
A demanda por reparações visa a que o Estado e a sociedade tomem medidas para ressarcir os descendentes de africanos negros, dos danos psicológicos, materiais, sociais, políticos e educacionais sofridos sob o regime escravista, bem como em virtude das políticas explícitas ou tácitas de branqueamento da população, de manutenção de privilégios exclusivos para grupos com poder de governar e de influir na formulação de políticas, no pós-abolição. Visa também a que tais medidas se concretizem em iniciativas de combate ao racismo e a toda sorte de discriminações.
} 
Porém, o que pensam os alunos? Para os alunos a temática Cultura e História Afro-Brasileira remete a preconceitos e discriminações. Os alunos evocaram situações de discriminação que presenciaram ou vivenciaram dentro e fora da escola: "Minha tia, quando vê um menino branco bonitinho diz pra minha prima vai lá, vai lá pra clarear a raça" (aluno). Ou: "Na minha sala ano passado tinha um cara negro e quando ele vinha com uma calça preta falavam que ele tava pelado" (aluno). E ainda: "Tem um aluno muito zoado, ele é negro e bem grande, mas ele não reage à zoação. Passam bilhete do tipo: todo mundo odeia o Joe. Contam piada. Os moleques acham engraçado isso, inclusive o menino negro" (aluno).

A associação entre preconceitos e discriminações negativas referentes a ancestralidade africana são recorrentes:

Eu estava no ônibus, um menino zoou dizendo "nossa tá um cheiro de churrasco aqui, tá um cheiro de menina preta". Eu fiquei constrangida. Se você chegar e falar o aluno vai entender, mas tem que conversar muito e insistir muito, tem que chegar lá e ficar batendo o pé naquilo (aluno).

E pode estar presente mesmo quando se emprega termos que, aparentemente, poderiam ter outra conotação: "Em minha opinião as pessoas não falam afrobrasileiros falam afrodescendentes. Quem não tem nada contra fala afro-brasileiro, agora quem tem preconceito fala afrodescendente com aquela voz meio arrogante" (aluno).

Os alunos relacionam o termo afro-brasileiro à discriminação e ao racismo. Contudo, os preconceitos e discriminações negativas que podem engendrar uma construção identitária a partir da não identificação com a afrodescendência são questionados e problematizados nas falas dos alunos. Também os conceitos expressos pelas palavras preconceitos e discriminações são interrogados, pois "preconceito e discriminação não é a mesma coisa" (aluno). Para eles, a discriminação seria a demonstração do preconceito através de atos.

Pelas argumentações, a Cultura Afro-Brasileira é caracterizada como um elemento que está incorporado à cultura nacional, que remete a descendência, a ancestralidade africana e a miscigenação étnica do Brasil. Tal significado que foi afirmado pelos alunos nos grupos focais está conforme a definição de Lopes (2006). 
Os alunos quando perguntados sobre lugares e situações em que ouviram falar sobre a Cultura Afro-Brasileira apontam para a escola. Uma das participantes do grupo assinala que na escola o vocabulário adequado é utilizado, enquanto que na rua, os alunos utilizam outros termos, em geral, de conotação pejorativa. Essas respostas evidenciam que a escola problematizou conhecimentos sobre africanidades e que sua abordagem foi significativa para esses jovens. Os alunos assinalam a presença desse conteúdo nas aulas de História, Geografia, Literatura e Educação Física: "Tivemos capoeira na Educação Física e o professor explicou de onde ela vem" (aluno). Também: "Estudei sobre Zumbi dos Palmares, sobre as culturas africanas, sobre as descendências dos afros. Em história e um pouco em literatura. Em geografia estudamos a economia da África que é precária" (aluno). "Eu aprendi sobre os negros que eram escravos e vieram da África" (aluno).

Os assuntos estudados se fazem, assim, presentes nas falas dos alunos. E mesmo fragmentados e com o envolvimento de apenas parte dos professores, todos eles afirmaram que é importante estudar História e Cultura Afro-Brasileiras. Os alunos parecem estabelecer uma ligação direta entre o que se estuda na escola e a forma como agem, indicando que o estudo desse conteúdo pode levar à compreensão e ao respeito, e, consequentemente, à valorização do afrodescendente na nossa sociedade:

\begin{abstract}
Eu acho que mudamos quando conhecemos mais, Mudamos a forma de pensar das pessoas sobre os afros. Mudamos completamente porque eles começam a ter certo pensamento, noção de como eles são e de que não devem ser chamados de neguinho. Com o passar do tempo as pessoas vão aprendendo como respeitá-los melhor, como conviver com pessoas assim e a deixar o racismo de lado (aluno).
\end{abstract}

A importância do estudo da Cultura e História Afro-Brasileiras na escola é, segundo os alunos, condizente com os pressupostos da educação multicultural. A educação multicultural adquire relevância na medida em que se destina a todos e engloba o combate ao racismo, a desmistificação do olhar sobre as religiões de ascendência africana, a releitura da escravidão e de toda a História. Conforme afirmam Salles e Silva (2008, p.160), os alunos devem "conhecer suas origens como brasileiros e como participantes de um grupo social específico compreendendo seu próprio valor e desenvolvendo atitudes de repúdio aos preconceitos". 
Buscando levantar outras pistas e aprofundar a importância que tem o estudo da história e cultura afro-brasileiras no cotidiano escolar, foi perguntado aos alunos se para eles este estudo pode influenciar a conduta de alunos e professores, e como resposta obteve-se:

Até o ano passado, eu tinha uma amiga muito preconceituosa, ela era japonesa e tinha preconceito com pessoas negras. Certo dia a professora começou a falar sobre preconceito, racismo, cultura e da história afrobrasileira e ela mudou radicalmente, totalmente, ela está namorando um menino negro (aluno).

Falas como essa parecem indicar que a atuação da escola pode mudar a forma de pensar e de agir dos alunos, contribuindo, assim, para a mudança da realidade social. Todavia os preconceitos na escola ainda existem e são vividos em relações conflituosas. As situações de conflito necessitam de um encaminhamento. Espera-se que medidas sejam adotadas para se alcançar soluções. Não obstante, os relatos dos alunos são recorrentes na indicação da pouca intervenção por parte da escola. Os alunos sinalizaram que não há uma política da equipe escolar para lidar com situações como as apontadas acima, restringindo-se à atuação isolada de um ou outro professor. As situações são, muitas vezes, consideradas como brincadeiras, o que acaba isentando o professor de agir: "Nas situações de chamar de macaco e essas coisas, a maioria dos professores acha que é brincadeira nossa" (aluno).

Destaca-se, no entanto, que dizer é brincadeira ou levar na brincadeira pode mascarar a violência do preconceito e da discriminação, que, por aparecer camuflada, não estimula reação, tendendo a ser naturalizada.

\section{Considerações finais}

Esta pesquisa teve por objetivo investigar o impacto que a promulgação da Lei 10.639 tem no cotidiano escolar. As vozes de alunos e as vozes dos professores expressaram que as temáticas afrodescendência e Cultura e História Afro-Brasileiras estão presentes na sociedade e na escola. Porém, o relato dos professores evidencia que o incentivo institucional oferecido pela Rede Estadual de Educação do Estado de São Paulo, em Educação Continuada e Permanente, tem sido incipiente no tocante à Lei 10.639 . 
A análise revelou que o cotidiano escolar é permeado por relações de conflito etnicorraciais que adentram o espaço escolar, evidenciando que relações de poder que se manifestam por meio de preconceitos e discriminações etnicorraciais estão presentes no cotidiano das escolas. O estudo indicou que a permissividade e a falta de limites fazem com que proliferem, no âmbito escolar, estigmas e manifestações de discriminação. Indicou, ainda, que poucas vezes são organizadas situações que levem os alunos a pensar sobre a História e Cultura Afro-Brasileiras, independente de quais sejam as suas ascendências.

Considerando que as Diretrizes Curriculares Nacionais para a Educação das Relações Etnicorraciais e para o Ensino de História e Cultura Afro-Brasileiras e Africanas foram instituídas em junho de 2004, ou seja, tendo menos que uma década de vigência, é compreensível a parcial inclusão dessas diretrizes no cotidiano escolar conforme foi constatado na escola estudada, o que, no entanto não deixou de reafirmar a importância dessa discussão no âmbito escolar.

No geral, os depoimentos sinalizam uma lacuna política na determinação das responsabilidades e no estabelecimento de metas para que a escola promova a igualdade etnicorracial. Talvez, por isso, as escolas não tenham um direcionamento claro sobre o ensino de Cultura e História Afro-Brasileiras, tampouco sobre como agir em situações que envolvam conflitos relativos às questões etnicorraciais. Nesse sentido é que quando situações de preconceitos e discriminações etnicorraciais eclodem nas escolas as tentativas de enfrentamento por parte dos educadores são isoladas, visto que não há uma postura coletiva da escola para enfrentá-las.

Entretanto, a escola é um espaço privilegiado para a realização de um trabalho construtivo que indique claramente que qualquer forma de discriminação é inadmissível. Para tanto, as normas de condutas da escola devem ser amplamente expostas, difundidas e sintonizadas para o fim dos preconceitos e discriminações.

Cabe à escola a adoção de políticas educacionais e de estratégias pedagógicas de valorização da diversidade, com intuito de superar a desigualdade etnicorracial presente nas praticas escolares contribuindo para uma sociedade mais igualitária.

A lei 10.639, na prática, não se resume apenas em ensinar mais conteúdos sobre a História e Cultura Afro-Brasileiras. É, também, uma questão de sensibilizar a atitude, de tocar no sentimento, nas categorias de interpretação do mundo. Processo 
que começa, conforme acreditamos, pelo desvelamento das relações de poder implícitas nas relações etnicorraciais que se fazem presentes no cotidiano escolar.

\section{Referências}

ASSIS, M. D. P.; CANEN, A. Identidade Negra e Espaço Educacional: vozes, histórias e contribuições do multiculturalismo. Cadernos de Pesquisa, São Paulo, v. 34, n. 123, p.709-724, set.-dez. 2004.

BECCARI. C. B. Discriminação social, racial e de gênero no Brasil. In: Portal DireitoNet. [2005]. Disponível em: <http://www.direitonet.com.br/artigos/exibir/1991/Discriminacao-socialracial-e-degenero-no-Brasil>. Acesso em: 26 maio 2009.

BARDIN, L. Análise de conteúdo. Lisboa: Edições 70, 1977.

BERGER, P. L.; LUCKMANN, T. A construção social da realidade. Tratado de sociologia do conhecimento. 22ed. Rio de Janeiro: Vozes, 2002.

BRASIL. Casa Civil. Lei № 11.645, de 10 de março de 2008. Disponível em: http://www.planalto.gov.br/ccivil_03/_ato2007-2010/2008/lei/l11645.htm. Acesso em: 15 mar. 2010.

BRASIL. Ministério da Educação. Parecer CNE/CP n.o 3, de 10 de março de 2004. Disponível em: <http://portal.mec.gov.br/cne/arquivos/pdf/res012004.pdf>. Acesso em: 17 jun. 2009.

BRASIL. Casa Civil. Decreto-Lei № 10.639, de 09 de janeiro de 2003. Disponível em: <http://www.planalto.gov.br/ccivil_03/leis/2003/l10.639.htm>. Acesso em: $10 \mathrm{abr}$. 2008.

BRASIL. Casa Civil. Lei 9.394, de 20 de dezembro de 1996. Disponível em: <http://www.planalto.gov.br/ccivil_03/leis/19394.htm>. Acesso em: 1 jun. 2014. 
GATTI, B. A. Grupo focal na pesquisa em ciências sociais e humanas. Brasília: Liber Livros, 2005.

GIL, A. C. Como elaborar projetos de pesquisa. São Paulo: Atlas, 1991.

GOFFMAN, E. Estigma: Notas sobre a manipulação da identidade deteriorada. Brasil: Zahar, 1963.

LIMA, H. P. Personagens Negros: um breve perfil na Literatura Infanto-Juvenil. In: MUNANGA, K. (Org.) Superando o Racismo na escola. 2ed. Revisada. Brasília: MEC, Secretaria de Educação Continuada, Alfabetização e Diversidade, 2005. p.101-116.

LOPES, N. Dicionário Escolar Afro-Brasileiro. São Paulo: Selo Negro Edições, 2006.

MARTINS, D. S. F. A Lei 10.639, o cotidiano escolar e as relações étnico-raciais: um estudo de caso. 2010. 112 f. Dissertação (Mestrado em Educação: Organizações Escolares) - Universidade Estadual Paulista. Rio Claro, 2010.

MUNANGA, K. A importância da história da África e do negro na escola brasileira. Jornal Subsídio, n.11, p.9-11, 2005.

MUNANGA, K. O preconceito racial no sistema educativo brasileiro e seu impacto no processo de aprendizado do 'alunado' negro. In: AZEVEDO, C.; GENTILI, P.; KRUG, A.; SIMON, C. (Orgs.). Utopia e democracia na educação cidadã. Porto Alegre: Ed. UFRGS/Secretaria Municipal de Educação, 2000. Inserir p. 235-243.

OLIVEIRA, A. G. de. O silenciamento do livro didático sobre a questão étnico-cultural na primeira etapa do ensino fundamental. Jornal Bolando Aula, Santos, n. 66, p. 5-7. 2005.

SALLES, L. M. F.; SILVA, J. M. A P. Diferenças, Preconceitos e Violência no âmbito escolar: algumas reflexões. Cadernos de Educação, Pelotas, v. 30, p. 149-166, jan.-jun. 2008.

SALLES, L. M. F. Jovens, escola e violência: alguns apontamentos sobre o processo de inclusão e exclusão simbólica de jovens. In: SALLES, L M F; SILVA, J M A P. (Org.). 
Jovens, violência e escola: um desafio contemporâneo. 1a ed. São Paulo: Cultura Acadêmica, UNESP, 2010, p. 87-103.

SILVA, A. C. A Desconstrução da Discriminação no Livro Didático. In: MUNANGA, K. (Org.) Superando o Racismo na escola. 2ed. Revisada. Brasília: MEC, Secretaria de Educação Continuada, Alfabetização e Diversidade, 2005. p.21-39.

TRIVIÑOS, A. N. S. Introdução à pesquisa em ciências sociais. São Paulo: Atlas, 1987.

VICENTE, J. O Dilema da Nação. Folha de São Paulo, São Paulo, 25 abr. 2007.

WATTHIER, L. A discriminação racial presente em livros didáticos e sua influência na formação da identidade dos alunos. Revista acadêmica multidisciplinar, Maringá, $n$. 16, inserir p.47-54, ago.-nov. 2008.

Enviado em Setembro/2012 Aprovado em Novembro/2013 